\title{
The potential role of network-oriented interventions for survivors of violence among refugees in Belgium
}

\section{Emilomo Ogbe ( $\square$ emihoms@gmail.com )}

Universiteit Gent https://orcid.org/0000-0003-2707-3405

\section{Alaa Jbour}

Universiteit Gent

\section{Ladan Rahbari}

Universiteit Gent

Maya Unnithan

University of Sussex

Olivier Degomme

Universiteit Gent

Research article

Keywords: social support, refugees, violence, network theory, sexual and gender-based violence

Posted Date: July 16th, 2019

DOI: https://doi.org/10.21203/rs.2.11464/v1

License: (9) This work is licensed under a Creative Commons Attribution 4.0 International License. Read Full License 


\section{Abstract}

Introduction Social support and social network members have been identified as an important factor in mitigating the effects of sexual and gender-based violence (SGBV) and improving the coping process for many survivors. Network oriented strategies have been advocated for among domestic violence survivors, as they help build on improving social support and addressing factors that alleviate repeat victimization. There are opportunities to implement such strategies among refugees, who are survivors of SGBV in asylum centres, however, this has not been fully explored. This study sought to identify key strategies and opportunities for developing peer-led and network-oriented strategies for mitigating the effects of SGBV among refugees at these centres. Methods: 27 interviews, were conducted with service providers $(n=14)$ and refugees $(n=13)$ at three asylum centres in Belgium. Deductive coding was performed independently by two researchers based on pre-identified research questions, when new findings emerged outside the themes, open coding was done. Data triangulation was used with findings from observations at these centres over a period of a year. Findings: Many of the refugees presented with PTSD or psychosomatic symptoms, because of SGBV or other trauma experienced during migration. Peer and family support were very influential in mitigating the effects and social costs of violence among the refugees by providing emotional and material support. Social assistants were viewed as an information resource that was essential for most of the refugees. Peer-peer support was identified as a potential tool for mitigating the effects of SGBV

\section{Background}

Social support and the positive influence of social network members are important factors in mitigating the effects of sexual and gender-based violence (SGBV), other forms of violence and life stressors, as well as improving the coping process for many survivors (Levendosky et al., 2004; Sullivan \& Bybee, 1999). The mechanisms and processes through which social support affects coping processes is complex and time dependent. It is also reliant on the structure of the social network and inherent capabilities of the individual (Schwarzer \& Leppin, 1991). A study comparing the social networks of women in abusive relationships with their domestic partners, compared to 'non-abused' women, found their social networks to be smaller, with fewer reciprocated ties. These women were also more likely to provide support than receive it, compared to non-abused women of the same socio-economic group (Katerndahl, Burge, Ferrer, Becho, \& Wood, 2013). Although abused women often played a 'central' role in their networks, mostly serving as a link between different members of their network and as a resource person, they had few people they discussed their problems with. In this paper, we define domestic violence according to Flury et al's definition as 'any act of physical, sexual or emotional abuse perpetrated by an intimate partner, family member or friend often encountered in a domestic environment' (Flury \& Nyberg, 2010).

Survivors of sexual and gender -based violence will seek help first through informal sources (friends and families) before more formal sources like medical centres and legal assistance. This, elucidates the need for closer attention to network members of survivors of violence when developing interventions (Sullivan 
\& Bybee, 1999). This is especially true for refugees and undocumented migrants, with the same national and ethnic identity, among whom stronger ties might exist than with service providers or members of the destination country (Smith, 2013). Smith's work on female refugee social networks revealed an evolving social network structure, with strong homogenous ties among people with similar national identities, and weak social ties with people from the host country. In Smith's work, these weak ties did not serve as sources of emotional or financial support for the refugees.

Network-oriented strategies have been advocated for among domestic violence survivors, as they help build on improving social support and addressing factors that alleviate repeat victimization (Goodman \& Smyth, 2011). They have also been used among other vulnerable populations like intravenous drug users (Latkin, Sherman, \& Knowlton, 2003), for HIV risk reduction strategies (Kelly et al., 1991) and to provide support for individuals with chronic conditions like diabetes (Vissenberg et al., 2016).

There are opportunities to implement network-oriented strategies among refugees, for example, involving family members and peers in mental health interventions, group therapy sessions (Hogan, Linden, \& Najarian, 2002) or interventions similar to mentor mothers (McFarlane \& Wiist, 1997). There are already existing network oriented interventions, specifically family-oriented interventions, focused on the mental health of refugees' which have been found to be successful (Weine et al., 2008). These strategies could also be implemented in different humanitarian settings.

This study sought to understand the social network and support characteristics of refugees at three different asylum centres in Belgium. The aim was to identify key strategies and opportunities for developing peer-led and network-oriented strategies for mitigating the effects of sexual and gender-based violence among refugees at these centres. In this paper, network interventions are defined as 'purposeful efforts to use social networks or social network data to generate social influence, accelerate behaviour change, improve performance and/ achieve desirable outcomes among individuals, communities, organizations or populations (Valente, 2012). As a result of our qualitative study, we also developed a theoretical model to explain the 'processes' and factors that determine how actions of network members influence the decision to access health care services and the different outcomes of these processes.

\section{Theoretical model}

The development of the theoretical model was based on:

1. a literature review of network and social support theories and interventions among refugees and survivors of sexual and gender-based violence

2. In-depth discussions with refugees who were survivors of violence, experts in the field of migrant health and sexual and gender-based violence, as well as economic theorists with expertise on network effects and game theory. 
The added value of this approach, was to ensure that the model reflected the realities of support structures of many refugees and sexual based violence survivors, as well as the important factors that influenced their decision making.

\section{Figure 1 Model explaining network effects on reporting behaviour of sexual violence survivors (Ogbe et al 2018)}

The proposed model discusses the way actions and efforts made by network members can positively or negatively influence decisions to access sexual and gender-based violence services by survivors of violence. We postulate that several factors related to the network characteristics of refugees will both influence their decision to access health care services, as well as the outcomes of their decision making process We have identified these factors as factor $A$, factor $B$ and $C$.,

\section{Network factors}

Factor A. Survivors and network members' attributes: These refer to 'intrinsic' characteristics of the survivor and network members, for example, gender, age, ethnicity/ race, and other related characteristics that could be defined as sociodemographic. An additional factor, we included into this category, is the concept of 'resilience'. The ability of refugees who are survivors of violence to cope with the psychological consequences of their experience of violence and trauma during migration, and navigate the challenges of adapting to a host country in a hopeful yet pragmatic way.

Contributing co-factor $A$ : Contextual effects: These are 'extrinsic' attributes for example the refugee camp or centre, existing laws and regulations regarding access to SRH services for refugees, availability of infrastructure and sufficient staff to address these issues, as well as a reporting mechanism for reporting cases of gender-based violence.

Factor B. Network members' reaction to the survivor reporting: This refers to the probability or chance that network members will react positively or negatively to the decision of the refugee to seek out health care services

Contributing co-factors $B$ : i) Effort required by the network members' to support or oppose: We assume that the network members' of a survivor of violence, are rational in thought. Hence, if it takes too much effort to support the survivor to seek healthcare services, this will influence their decision to provide support. Hence, the higher the personal effort or cost to support the survivor of violence, the more likely they will be neutral or oppose the decision of the survivor to report or seek healthcare. An example of effort could be the financial cost, time cost or emotional burden of providing support. 
ii) Degree and centrality measures of network members: Degree and centrality measures refer to the 'power' or level of influence, the network member has within the refugee's social network. High degree (highly influential and connected) members who oppose or support the refugee to access health care service, will have more influence on the decision making and the actions of other network members, than network members with few strong ties and lower levels of influence.

Factor C: Constraint and Cohesiveness of the network: In our model, we assume that within a network, the extent to which, network members' actions and perceptions can prevent the refugee from reporting or accessing health care is dependent on how cohesive the network is; by 'cohesiveness' we refer to the strong ties between groups, that ensure the members of the group remain linked.; A constrained ego (network member) within a cohesive network, is one in which the other people in the network are connected to each other, and the ego's actions and perceptions are controlled by his or her personal network (Valente 2010,)

\section{Threshold and resilience}

In our model, we propose that the additive and detrimental effect of these factors will result in several outcome scenarios based on the idea of a threshold. Survivors of violence will seek health care with positive consequences if the additive effects of Factors $A, B$ and $C$ and their co-factors exceed this required threshold level. Below this threshold level the benefits of reporting would be non-existent, or reporting might cause the refugee such negative consequences, that it is not in their interest to seek health care services.

In developing this concept, we also take into account unexplained characteristics like resilience, which we understand is difficult to measure. When we define resilience, we refer to the innate ability of a survivor of violence/refugee to cope with external stressors and challenges, in spite of the absence of resources and support.

By mapping out these factors, we hope to provide a way to map out with qualitative and quantitative factors, the way social networks affect decisions to access health care among refugees, not only in cases of sexual and gender-based violence but other stigmatizing situations, and for example when refugees are dealing with mental health issues or infectious diseases like HIV/AIDS.

Outcomes from Network effects: We describe several potential outcomes based on the concept of a 'threshold effect', looking at the summation of 'positive' and negative influences of network members, as well as intrinsic and extrinsic factors that might influence decision making, already explained above. We 
have divided these outcomes based on whether the level of support is equal to, less than or more than the level of conflict and the decision the survivor takes.

- Outcome 1: Survivor reports, and the level of support is greater than conflict, which would be the best outcome for the survivor. In this scenario, the survivor will require less effort to report (hence, less individual cost), as their network members will provide sufficient support and resources (information, emotional and monetary support) to mitigate whatever stigma or negative consequences they will experience, after reporting.

- Outcome 2: The level of support and conflict is equal, but the decision to report is based on survivors' perceived benefit of reporting, as opposed to the actual benefit. In this scenario, there are several challenges to reporting their experience of violence and seeking health assistance. These challenges are equal to whatever support or benefit the survivor might gain from seeking care. Hence, the decision to report is more heavily influenced by the 'perceived' personal cost to the survivor of violence, and less on the existing challenges or benefits. We assume that most people in this situation, do not report or seek health care, unless there is an intervention.

- Outcome 3: The level of support is less than the level of conflict caused by reporting but the survivor decides to report. In this scenario, the consequences of reporting, for example stigma, loss of resources and support network, etc., far outweigh the 'social' benefits of reporting. However, the survivor goes ahead and reports their experience of violence. In this situation, this survivor of violence requires more support from health workers, as well as psychosocial counselling and follow up. These survivors might be viewed as having more resilience, but are actually in a more vulnerable situation, as a result of seeking care

- Outcome 4: The level of support is less than the level of conflict caused by reporting but the survivor decides to not report, in this scenario, the survivor of violence makes a rational decision to not seek health care because of the negative consequences of reporting. However, in so doing they are unable to get treatment and the needed psychosocial counselling required. Also, in an instance where the perpetrator(s) are part of the family, there might be repeat incidents of abuse.

\section{Methods}

Different qualitative research methods were triangulated to cross-validate research findings. A combination of ethnographic methods, specifically observations were combined with key in-depth interviews between November 2016 to February 2018. The observations were conducted in three centres, two of these centres were located in East Flanders and the third was located in Brussels. Table 1 provides 
more detail about the centres and time allocated to each centre. Table 2 gives more specific information about service provision at the centres. Ethnographic methods were employed to help us understand the pathways of care and the daily life experiences of people who lived in the different centres selected for the research. Observations involved following-up with consultations, assisting with daily tasks required in the centres' and attending social events with the refugees. Selection of the centres was purposive and done in collaboration with the Director of Medical services for the Federal Agency for the Reception of Asylum seekers (Fedasil), as well as with researchers and service providers working with refugees.

The purpose of choosing different types of centres was to assess how the structure and organization of asylum centres and policies influenced the perception of support by the refugees in the centres and the relationship between the service providers and the refugees. Ethics approval for the study was gotten from the Committee for Medical Ethics, University of Ghent teaching Hospital. Approval to conduct the study at the refugee centres was obtained from FEDASIL.

Purposive sampling was done to ensure that research participants were a mixed group of service providers (social workers, psychologists, nurses, education workers, medical doctors) and refugees (men, women). Informed consent was obtained from all participants and permission taken for audio recording. We stopped interviewing more research participants, when thematic saturation was reached. Research participants approached for an interview, were encouraged to take their time to review the informed consent form or think about the research, before agreeing to sign the informed consent form and be interviewed. For the refugees recruited at the clinics, the research project was always introduced by a service provider, after the consultation was finished. They were assured that participation in the research project was voluntary and would not influence their asylum procedure or access to services. Information about the research was also made available in Arabic, French, Dutch, Farsi, Pashto and Dari and placed in common areas in the different refugee centres. An additional Focus Group Discussion was done based on the request for a sexual health workshop by one of the centres. The workshop was done in English, Dari and Pashto.

Deductive coding and a thematic analysis was done based on pre-identified codes based on the research questions by 2 researchers. When new findings emerged during the coding process, new codes were developed, Triangulation was done with findings from observations done at these centres over a period of a year. The key findings are discussed in this paper.

\section{Key Findings}

We have described the key findings based on the theoretical framework described above.

\section{Contextual factors, susceptibility and internal coping mechanisms (Factor A)}


We classified several factors related to respondents' family situation, their experiences of violence before and during their migration to Belgium, as well as, the structure of the asylum centre, including service provision and health system factors, as contextual factors.

\section{Background of research participants}

Twenty-seven respondents were interviewed during the research projects, All respondents were above the age of 18 and were able to give informed consent. Some of the refugees were survivors of gender-based violence and torture (4 respondents). The service providers were mostly Belgian, apart from 1, and consisted of social workers, education workers (focused on life skills and supervising daily activities in the centre), medical doctors, nurses and psychologists. The refugees were from East and West Africa and West Asia. A third of the refugees had at least a bachelor's level of education and cited political unrest and economic reasons as some of their reasons for migration. Specific details about the countries they come from have been excluded to protect their anonymity and prevent stigmatization that might arise from conclusions of the study. During the interviews, issues around integration were identified as important by all the respondents but more by the social workers. This was defined as being more than just understanding the local language but also behaving in what was considered a 'culturally acceptable manner'. The term 'culturally acceptable' was described in terms of adhering to an acceptable dressing style, manner of speaking, 'ways of conducting oneself' and hygiene. However, one could argue that these integration issues were not cultural per se, but more related to ideas around propriety in Belgium and conflicts with different behavioural attitudes and diversity.

'...social network with local people. It is not an easy task. Lots of cultural differences, first they have a cultural shock, a lot of differences, ..., you need too much time to integrate.' (Medical translator and doctor, Refugee)

....you walk on the street and you see, a lot of people say. we see these people (refugees) and we are afraid...that's a small thing, I think the way you dress is less important than the way you conduct yourself. (Social worker)

The social worker discussed the underlying tension or fear among the local population, as what could be referred to as 'the fear of difference', specific issues raised were the 'loud manner' of some migrants, which were perceived as aggressive, or the unruly behaviour of migrant children from specific backgrounds.

The service providers which consisted of medical doctors, social workers and nurses, all had prior experience with working with refugees/ and undocumented migrants but few had experiences of 
migrating and living in another country, which may have implications for how they experience or perceive the needs and appropriate services required for refugees and undocumented migrants.

The duration of stay in Belgium varied from 3 months to 7 years among the research participants, who were refugees. However, there was no reported association between length of stay in Belgium and perceived level of integration. It is important to point out the complexities of integration in Belgium, which are heavily influenced by linguistic and regional politics and can be ether broadly defined as assimilationist or multi-culturist. The multi-culturist-interventionist type of policy and approach, which is more common in the Flemish region is characterized by compulsory civic and language classes, and a focus on migrants adhering to the Flemish identity. The assimilationist colour blind approach is more common in the Walloon region and has a policy that allows room for diversity, hence the lack of compulsory language classes. These differences may add layers of complexity to the definition of cultural integration in Belgium (Adam \& Jacobs, 2014).

\section{Asylum process}

The asylum process arose from most of the interviews as a crucial component and an indicator of the well-being of refugees. Most of the respondents (refugees and service providers) spoke of the difficulties of being 'in transition' being moved from one centre to another, while awaiting the decision on their asylum. This was a factor that had a significant effect on their psychological well-being. These changes and frequent movement among people still within the asylum process, might make it difficult for sexual violence survivors to access needed care, as well as needed follow up, psychosocial counselling and medico-legal procedures.

'there's a huge difference, in terms of the challenges, the uncertainty, you often see it in the chain from the asylum procedure, to obtain a status, that makes a huge difference both in the positive and the negative sense, it impacts your mind...positive is what gives security and safety, the feeling that I can now start my life, Negative(asylum status) is that you begin to lose many support structures in terms of the asylum centre and that feeling of stability...'(Service provider, psychologist, female).

Harrell-Bond and Voutira (1992) described this feeling using the term 'liminality', an in-between situation that applies not to only economic and social security, but also to legal and psychological situations. This uncertainty makes the lived experiences of many refugees precarious, for as long as they are within the asylum process, they can be moved from one part of the country to the other, disrupting the existing social networks they might have formed as well as a feeling of security they might have developed. 
'the situation here is so hard, the people here are placed and replaced and they have to change from centre to centre and schools it is so inhuman....'(Service provider, doctor, male)

Most of the refugees and health workers interviewed for this study were reflective while describing their experiences providing or accessing healthcare at the centres. Most of the refugees expressed an appreciation for the services they were provided at the different centres, while also expressing dissatisfaction at barriers, which are described later in this paper. The service providers also seemed to understand the budgetary and human resource challenges encountered in their provision of services and described different strategies for dealing with this.

\section{Experiences of trauma and psychological distress}

Physical violence was the most reported type of violence among the respondents. There were different examples of physical violence reported including female genital mutilation, physical assault between refugees, violence from smugglers and intimate partner violence. Most of the respondents discussed this situation with the social workers. One of the most common barriers discussed was the cultural expectation or shame linked with domestic violence (physical or sexual). Responses to reports of physical violence were varied, from 'no action taken' to provision of psychological counselling.

Physical mostly, physical violence is often [reported by] men and women, but sexual violence either people are not disclosing, (or there are) rare cases,..., I have seen myself. I think this exists but might be because of shame, taboo or cultural differences they are not going to disclose it. (Research assistant, Male)

Experiences of torture: Some of the service providers reported instances of torture among the male refugees. They also discussed the difficulties with getting these men to share their experiences of trauma. While all the service providers recognized the importance of providing counselling and psychological care to the refugees, most centres had no in-house psychologists present. External referrals were required, however, not all psychologists were willing to work with refugees and undocumented migrants. A commonly cited reason for this was the language barrier. Most of the service providers had to develop a network of psychologists who had experience working with refugees and were willing to conduct therapy sessions with a translator. 
Yes, of course I would never say, this one has been tortured, but I could say to the reception or to the nurses, don't disturb us now, because it is a heavy conversation. So that would create like a kind of bubble... Especially because we had men who had been raped, they would never talk about this in their interview, because of the shame and trauma, it was too big. And in this way, a psychologist ... we had a conversation about torture, and I would never stop it at that, because then the story is out, but the evil spirit is also out. So, we need to provide counselling and afterwards... There were some very good psychologists, (with) whom I would make sure that the people would go there for follow up and for treatment. (Medical doctor, Female)

From the interviews, it seemed there was a gender bias in reporting behaviour among men and women. Women were more likely to share their experiences of torture or sexual and gender based violence than men. A reason for this, could be the absence of targeted interventions for men who experience SGBV or adequate screening procedures for them. We would like to advocate for a gender lens to be applied to screening exercises done in the reception centres, with an understanding that men and women of different ages, gender identities and sexual orientation might report experiences of sexual violence and torture differently.

Sexual violence. Though there were instances of sexual violence, disclosure was difficult and often dependent on the attitude of the health professional. Health care professionals who probed deeper for sexual violence risk, were more likely to have patients disclose their experiences.

... I see a lot, and I think not all are... I try to ask, it is not easy to ask directly, for women it's not easy to answer... I am clear that lot of people (have experienced) sexual violence...not only women, we have a lot of young men from Afghanistan (have experienced) sexual violence too. So, I try to ask whenever it's possible. But I see a lot, more than normal with my consultations... (Medical doctor 1, Female)

The medical doctor quoted above repeatedly stressed on the sensitive nature of screening for SGBV, a strategy she used, was to ask a lot of general questions before discussing sexual violence. Another medical doctor affirmed:

... A lot. Oh, they were very open about it. But never, almost never from the beginning, of course. That's why I think this intake was ok, because we wanted to give them the feeling that there was an opportunity to talk about it. And for many times we opened, we were very active in starting a conversation about this (Medical doctor2, Female). 
This comment reaffirms the importance of screening for experiences of violence, as this provides an 'opening' for refugees to discuss their experiences.

\section{Common health problems: psychosomatic symptoms}

Some of the most common health problems, the respondents presented with at the health clinic were psychosomatic, it was rare for them to present at the clinic and directly report their experiences of SGBV or torture. They only agreed to share their experiences of violence after several discussions. Psychosomatic symptoms were often related to experiences of trauma, during their migration journey or in their home country.

...it is mostly combination of anxiety related problems including sometimes Post Traumatic Stress Disorder, and sometimes more severe problems like psychosis. Sometimes stomach pain, breast pain, and anxiety related problems like flashbacks, and depression of course. Often related to a combination of traumatic experiences and losses, born in uncertain situations, difficult events...(Psychologist, female)

...long time, long time. But support here (in Belgium) because sometimes I couldn't sleep, I would dream about it but they gave me some tablets to help me sleep. I used to take them but after some time I stopped because I wanted to sleep in a natural way. I am afraid, still have them with me. Sometimes it happens, I can spend one week without sleep, morning, evening I don't sleep, and I am strong. But that is not life... (Refugee, female)

These findings show that service providers need to spend sufficient time discussing with their patients/ clients and probing for experiences of violence, as discussed above. It also requires that most medical centres ensure that they have the right referral pathways, so they can ensure survivors of violence identified have the right access to psychosocial support.

\section{Co-factor A: Contextual Factors}

Contextual factors such as cultural norms and health system factors were also reported by most interviewees as influential in their decision making to access healthcare services. 


\section{Cultural norms around IPV.}

Family network members, key players and reporting of gender-based violence: Family members of a survivor of violence could influence their coping strategies and attitudes towards reporting their experience of violence. In a case of a female survivor of domestic violence, her mother's support was highly valued as it gave her the psychological support required. Her mother told her to cope with the experience of domestic violence, as it was a cultural norm for husbands to sometimes beat their wives. This example outlines the complexity of family relationships and reporting patterns. Family members might be able to provide functional support to survivors of violence and aid them in coping with stress and psychological effects, and still discourage them from reporting. In some cases, the family member might be the main aggressor, and more interested in preventing the reporting of violence. Hence, network interventions that focus on key players (very influential network members) would have to take into account the complexities that exist in social networks with family members.

\section{Health system and health worker responses}

In general, health service providers, social workers, nurses and doctors who provided services to intimate partner violence survivors, referred the survivors to psychologists, with their consent. The responses from these service providers ranged from supportive to ambivalent.

Opening hours: There was a reported disconnect between refugees and service providers' expectations about availability and opening hours. The working hours of the centres were sometimes perceived as a barrier for access to healthcare for most of the refugees, however, for the service providers it was very important for them to have that structure to enable them function effectively. When the opening times were not respected, this was often viewed as 'crossing boundaries' or 'being disrespectful'.

... But I always give the signal that it is possible to come, if they want something, and I keep reminding them. But they also have to follow the rules, because it is not because you are a loner and one time you make a decision you come and ask for help, if you do it in the break, it is break time, you are not getting special treatment... (Social worker, female)

...yeah, yeah, it's been easy (to access healthcare). The problem is that they just open for two hours. But the service is good when they try to do everything, and when they can't they transfer you to the big hospital. If you don't have an appointment, they can't. But they do their best' (Refugee, female) 
. It is important to note that the concept of availability is not the same for service providers and for refugees (service users), and this could influence how survivors of violence perceive the availability of support for them. It is important that service providers take into account that specific vulnerable groups, for example, survivors of violence might require access to support services that extend beyond daily working hours. Creating alternative services, like chat lines or emergency support could make a difference in access to healthcare for these groups and mitigate harmful consequences. Also, from the human resource perspective, understanding the need for extra hours and more staff, referral pathways and adequate compensation for staff, can prevent burn out and motivate service providers.

Limited human resources. Some of the respondents reported difficulties in accessing services due to the lack of sufficient human resource. This problem also limited the ability of service providers to provide sufficient assistance and support to the survivors of violence

...I know a lot of people came once or twice to the nurses and then say I don't want to come back because it not good. Lots of people think that medical services (are) not good because it's difficult to access the doctors because there are lot of people, we don't have sufficient spaces and workers... (Medical doctor, female)

Lack of trust and ambivalence from service providers. Trust arose as an important factor, that could also be enabling and encourage disclosure of experiences of violence. It was also a barrier when there is a lack of trust present.

... Many are willing to discuss but there are parts that are hard to express. And it largely depends on the situation they were in. if they are at peace to talk in a quiet stable situation. For some it's hard to talk about because it reveals lots of emotions. Sometimes they feel like avoiding those emotions because they are too tough to feel. It depends. I feel there is lot of distrust preventing them to talk about it. Protecting themselves. It depends... (Psychologist, female)

In some cases, when the survivors of violence reported their experience of violence, they were met with ambivalence from the service providers which discouraged reporting of violence.

... [breathes] last time I was passing by the block F, I had come to see my assistant, I heard in one office one lady telling that one guy was abusing her. But sometimes these things happen. [And even if they talk to the assistant they do nothing]. I don't know... they just give them advices ... like I heard even before I came to PC [centre] one lady was telling that one guy was abusing her, the assistant was laughing, did 
nothing [reports of abuse taken very lightly, no redress I[sic]... but I heard that later they changed her room. (Refugee, Male)

Medical centres that provide care to refugees or undocumented migrants, often have a huge demand with limited resources, making it difficult for many refugees and undocumented migrants to develop relationships of trust with their service providers. However, it is possible for these relationships to be built over time. For example, most refugees interviewed developed good relationships with their social workers because of sustained interactions over time. In centres, where refugees saw a particular health provider over a long period of time, there was also more trust between the provider and refugee.

\section{Factor B: Network members' reaction to the survivor reporting}

We describe below several factors we identified, that might mediate network members' ability and reaction to experiences of violence.

\section{Communication:}

Inability to speak the language of the service providers was often cited as a barrier to disclosure of experiences of violence and also a limitation on the service providers' ability to help the refugee. This also limited opportunities for integration into the society. Specifically, for refugees who experienced PTSD or mental health issues, this barrier was significant as it limited opportunities to get psychosocial counselling, as well as isolated the survivors of violence. Hence, limited the efforts of service providers to support survivors of violence or other kinds of trauma.

... They are not used to disclosure, there are many barriers to disclosure. And there are more barriers of disclosure when the woman is in a more vulnerable position. This can be because she is without papers, does not speak the language, because she depends on that guy, he supports her, especially because she does not speak the language. (Gynaecologist, female)

...so we're supposed to refer the patients, who were having psychological troubles, to psychologists or therapists outside of the centre. But of course, because of the language barriers and because of a shortage of interpretation services and because of attitudes of local therapists and so on, and lack of experience in working with this population. We did most of it ourselves, unless we say that there was really a psychiatric problem, then we would send them to psychologists or psychiatrists or a mix of them, of whom we knew that they had experience and willingness to work with this population... (Medical doctor, female)

Page 15/31 


\section{Lack of power.}

Among some of the respondents interviewed, the inability of members of their social network to influence 'outcomes' affected their willingness to discuss their issues with them. In most instances, the inability of the network member to influence the asylum process or ensure access to resources, discouraged them from seeking help from these people.

'hmmm [pauses] I don't think because I just said, I specifically know 2 persons that they don't do politics, they can talk of my problems, if something happened to me, no, they don't have voice...they are citizens like any simple citizens, so they cannot say anything if something happened to me'(Refugee, male)

This comment draws attention to the fact that the presence of a large social network for a refugee and survivor of violence, does not necessarily translate to increased access to resources. The network members of the survivor of violence must also be perceived by them, as able to positively impact their circumstance, either through functional or instrumental forms of support.

\section{Co-Factor B: Effort required by the network members' to support or oppose}

From the interviews, efforts required by family members, friends and service providers, did not come up as an issue or factor that influenced the level of support. However, in one interview with a political refugee, she mentioned that it was impossible to get support from her father because contact (via phone) would put him at risk. In this case, the effort and personal cost required by her father to provide emotional or financial support to her, was too high. The same fear of persecution of family members, arose from other conversations with political refugees who had survived SGBV and whose families were still living in their home country. In most of these cases, there was no contact from family members.

From interviews with service providers, the personal cost of working extra hours or providing care during 'lunch hours' could serve as a barrier to access. Some of them were unwilling to do this. Hence, our earlier recommendation for training, recognition and compensation of extra working hours for service providers.

Factor C: Costs of effort for the survivor to report or not, degree and centrality measure of network members (constraint and cohesiveness of the network) 
Cohesiveness of the network: The closeness of social network members of refugees who are survivors of violence (sexual violence or torture) can encourage or deter them from reporting their experiences of violence during a medical consultant or to their social assistant.

'Yeah. And also, if the, for example, there is abuse in one family, ehm, and the family is here, there is more pressure from the family members not to tell anything instead of, there is woman, or a man, coming here and has been abused, but here she is alone, maybe there is less pressure from the family' (Social

\section{Assistant, Female)}

In many situations, especially if the asylum claim is made by a whole family, and there is an incident of SGBV, where the perpetrator is a family member, it would be very difficult for the survivor to disclose and seek help for the incident because of the implications (the asylum process) for the whole family. In other instances, the dependence many refugees have on family and social networks for emotional and financial assistance, can also negatively influence their ability to disclose incidents of SGBV within the family circle. Understanding these dynamics can be helpful for service providers and researchers, in understanding the barriers to access to healthcare.

\section{Co-factor C: Degree and centrality measure of network members}

Among refugees interviewed, it was difficult to assess which refugees were 'central' to their network and were key players. However, it was clear from some interviews, that certain people had more authority and more contacts with different refugees than others. Also, during collection of pilot data and ethnographic work, it was clear that some family members' or friends' opinions were more valued than others in decision making. In some instances, especially when it was about navigating the legal and social system in Belgium, the perspective of the social assistant was more valued, or another refugee with more years of experience of living in Belgium. The implication this has for SGBV survivors, is that if SGBV interventions are directed to individuals, and influential members of their network oppose their decision to access health care, this will make it very difficult for the refugee to receive the necessary emotional and physical support required, and might even result in isolation from other members of their network.

The Bridge: During the interviews, I identified people whom Valente (2012) refers to as people with bridging properties within a network, they were often people who had been in the centres for less than 6 months, had few social network members, were bi-lingual and had friendship networks that were heterophilic. In a microsystem, were most people sought friendships with people they viewed as being similar, bridges were often people who had friendships across 'cliques'. Though they had close friendships with people from their own country, they were likely to identify people from different countries as being part of their friendship network. They would not be identified as key players/ opinion leaders in a 
network analysis, but during my interviews and subsequent informal conversations with them, they were the ones who expressed more of an interest in my research project and proffered specific recommendations to address gender-based violence and its effects, that were based on peer-support. I ended up engaging some of these people as volunteers in my research project. I think these are the people with the greatest potential to effect change, especially in complex network structures, like those found in the centres I worked in.

'No, no [responds to question about having friends from the same country]... from other places like Rwanda, Congo, Niger, Ivory Coast, Kenya, Morocco, yeah, [the friendships are helpful]...One day, was talking to a staff at PC [centre] regarding as we are coming from different countries, we have different cultures, many things, I was telling them like to do one meeting for all people at PC... for some people who, how to say it, who in their life had difficult times, they want to be consulted [and speak about it].. because talking about it, you will feel well... [Male, refugee]

The refugee I spoke with above supported the idea of getting different refugees and nationalities together and consulting with them to jointly develop solutions to address their past experiences of violence and trauma and develop sustainable solutions.

\section{Type of support groups identified from the research project}

\section{Support from family members}

Family support was cited often as a source of emotional support, that buffered the psychological distress from the migration process and from the experience of structural violence,

Yeah, I have been in contact (with family members) you can say that they help. Not financial. It is like a psychological support (which helps) - (Male, refugee)

Other forms of family support included instrumental support, but this was not mentioned often. Instrumental support was mostly financial support or connections made through family members that facilitated the migration process. However, after they left their home country, most of the support received from family members was psychological, or in some cases, the respondents were reluctant to let their family know how dire their situation was and preferred to not be in contact with them.

In some cases, family members were seen as possible stressors, or unable to proffer any help. Hence, some of the refugees would rather not disclose their experiences to them. 
$:$ The other guys (family members) I don't want them to know where I am. The reason why I am here is the problem I face with (some of my) family members... because my father was in ..a polygamous marriage,.. so I am supposed to be the one to take care of the family... by knowing where I was they try to kill me when I was in Cameroon. So it will be good for me to be apart... (Male, refugee)

The recognition that the presence of family members might not be positive is important while developing social network interventions for survivors of violence, who are refugees and other vulnerable populations. Analysis or probing to understand the quality and type of connections between network members should be a pre-requisite before mapping or developing social network interventions.

\section{Support from friends:}

Among many respondents, peer support was often the most common source of support sought and received, and the level of support was mostly classified as good or fair. 'Good' referring to support that was perceived by the refugee as making an impact on their daily lives, and 'fair' as irregular assistance. Peers were cited as sources of functional and instrumental support, and sometimes helped to buffer stressful factors, by listening, providing information and facilitating social connections required by the refugees. In many of the centres, there was a mix of different nationalities and languages, many refugees sought people of the same nationality, who spoke the same language as friends. In a few cases, especially for refugees with children, they sought people in the same 'situation', specifically refugees with children whom they could communicate with. The reasons for doing this differed, for some the fact the people they met spoke the same language and had the same culture, was reassuring for them. Especially in a context that was different and filled with a lot of uncertainties regarding their future and opportunities. For others, through these networks, it was easier to get functional support, specifically information and resources that helped them improve their socioeconomic status. Seeking and receiving peer support was associated with seeking social support from other sources, like social assistants and family members. Among the survivors of violence, survivors who sought help from friends, were also likely to have other sources of support from their network, like social assistants and it helped with coping with psychosocial distress.

'...yeah. So it was leaving everything to me, cleaning the house... And when I used to come back I was really sad, so one day he tried to beat me [the husband]... it was first time, so the (social) assistant is trying to help. It happened. You can't deny it didn't happen . I talked to my friend living here. Last time I talked to her. And assistant of course,... yeah it helps...'(Female, refugee) 
...No, I do not have family here... But actually I know some of the Guineans and Cameroonian guys with whom I am sharing, but apart from that I don't have any family or friends here... I cannot say if they are friends but because I am in some country where I don't know anyone, I wanted to have somebody I can talk to, I can... I don't know... They are naturals (refers to same nationality).... Made them my friends (Male, refugee)

Respondents reported peer support to have a buffering quality from a lot of stressors present in their daily lives. These friends provided emotional support, or information regarding opportunities. For a refugee who was a single mother and a survivor of violence, having friends that could look after her daughter while she ran errands or looked for jobs, buffered some of the psychosocial effects of the experience of violence, as well as what she perceived to be the difficulties living in the centre. For another survivor of violence, being able to speak sometimes with friends she trusted, alleviated some of her psychological stress, as she was unable to speak to a lot of people, because of fear that, that would affect her asylum status.

\section{Support from social workers:}

In centres where the medical service were provided within the centre, an 'intake' procedure was in place for new refugees who are sent to the centre by the commiserate. In many cases, the social workers were responsible for giving an introduction or orientation to the centre, afterwards a medical intake was done by the nurses, which also involved a screening exercise for tuberculosis and other infectious diseases. Other illnesses or ailments reported were addressed by the nurse if they were perceived to be not 'serious' or not requiring prescription medication. For many survivors of violence and torture, this meant they sometimes shared their experiences of violence with the social worker and might never share their experience with the doctor, unless the doctor probed and screened for experiences of violence specifically.

'I think when they arrived in the centre there is a social intake with a social worker and she explains how the roles are and also explains there is a nurse here you can see her you can come to her if you have questions and this is the first pad which be done by the social workers and they come to see us but if they do not come to see us we do not search for them normally there is a flow of info about a person, then Fedasil calls us if there is a special medical issue then we know it before, but normally people one day they will come to see us, but the social worker has to say you have to take your medical profile to your nurse and the most of the people do this' (Nurse, female).

'I first... I didn't know it was important to come to a doctor. Just went to the assistant. She is the one who took me here' (Refugee, female) 
Most of the respondents identified social assistants as sources of instrumental support, people they sought help from when they required tangible things, and not emotional support. For survivors of violence, who were willing to discuss their experiences, they were more likely to discuss their situation with the social assistant than with any other service provider. There was an associated perception that discussing issues with the social worker would provide tangible solutions. The dependence on social assistants is usually more in the 'beginning', when a lot of refugees are not aware of the existing social structures, but as time passes and they become aware of the existing infrastructures, they rely on the social workers less. Probably, because they have also built external networks and are more clear on how to navigate the social systems.

The time dependent nature of sources of support should be taken into account when developing relevant interventions; as SGBV survivors who are refugees will build their own network after some time, and there might be a need to combine service provider based and more peer based support interventions for refugees who have spent some time in their host countries.

\section{Threshold and Resilience}

In our conceptual model we postulated that for survivors of violence to access health care, they would need to achieve a threshold, a minimal level of support that was beneficial enough to compensate for any potential conflict with network members or socioeconomic losses, reporting might result in. Through our interviews, and discussions and observations we found that the quantity of connections did not influence access to health care services or help seeking behaviour. The quality of the connections was more important and this was different for every refugee interviewed. Though this observation is not new, its relevance should be noted in developing peer based interventions, a focus on quality of interactions and perceived value of relationships is important. In relation to this is the concept of resilience and the effect this has on the threshold effect. Valente (2012) discusses the importance of 'low threshold' individuals and their roles in disseminating evidence. These individuals required less persuasion and support and were quick to take up new ideas and technologies. If we link this concept to resilience, we believe that individuals who are able to cope better with stress, require less support to take the initiative to access care and health. Pulvirenti and Mason discuss how high levels of resilience among female refugees, translated into lower prevalence of long term mental health difficulties, after experiencing violence compared to the general population. Understanding this concept and incorporating it into research and interventions targeted at refugees could improve outcomes (Pulvirenti \& Mason, 2011). Resilience might explain low rates of screening of violence, as refugees who are survivors of violence might perceive their experiences of violence as part of their 'new norm' given their prior experiences of violence during migration. Also, incorporating this concept into designing intervention requires consultation with refugees and discussing priorities and interventions that are more useful to them, which might be very different, from interventions developed when the 'victim' rhetoric is used. 


\section{Discussion}

Network - oriented interventions have been widely used in public health for different types of interventions including but not limited to smoking cessation, cervical cancer screening, diet and weight management and HIV prevention with different target populations, for example, sex workers and intravenous drug users (Rachel C. Shelton et al., 2019). However, there is limited evidence of the use of network interventions among vulnerable groups like refugees.

The use of network theory or social network based interventions involving refugees requires an understanding of the context and the different factors within network interactions, that might influence decisions to access health care. Our research findings indicate that the quality and perceived importance of connections is a key factor to developing peer based or network interventions, as compared to the number of connections. The popular assumption that, the presence of friends and family confers a protective barrier to sexual and gender based violence is not always correct as provided by examples from our interviews, and this kind of information can be teased out from respondents during the screening process. This finding is similar to Llyod's work on refugees in Australia, which shows that family and friends can be important sources of information and support, but specific harmful cultural beliefs shared among close knit or cohesive networks can be a deterrent to accessing health care (Lloyd, 2014). Although, in some cases where family and friends are supportive, this might provide the survivor of violence with enough impetus to report their experience and seek health care.

Context, specifically the existing asylum policies and processes, health system barriers as well as other barriers like language are of equal importance in developing network based interventions. Peer support might be useful in providing information, emotional support and resources but challenges experienced during the asylum process, could have a deterring effect on the willingness to access health care. The psychological distress experienced by many refugees during their migration process, as well as the uncertainty regarding their status in the new country can take its toll on their psyche, and ability to utilize existing services(Laban, Gernaat, Komproe, Schreuders, \& De Jong, 2004). The language barrier is an often overlooked factor but is significant in ensuring access to health care, information and resources (Asgary \& Segar, 2011). In some settings, translators where used when available, as well as inter-cultural communicators, but these interventions are not systemic or widely used in all asylum centres.

Expanding the definition of networks and incorporating service providers, like social workers, advocates, doctors and nurses into developing support interventions is important as discussed earlier in the paper, and identified in other studies done with refugees in high income countries (Burnett \& Peel, 2001). For some refugees, these contacts serve as the first and only source of information and resources. Also, addressing values and assumptions about refugees among social workers and doctors is important. This is an overlooked step in many asylum centres, as refugees might have specific challenges, that are different from the general population, which social workers and doctors in the host country might be unfamiliar with. Understanding concepts like resilience and the need for better screening processes especially during the intake process at asylum centres might improve identification and adequate referral 
processes for survivors of different forms of violence at the centres, especially for mental health issues like depression and post-traumatic stress disorder arising from experiences of SGBV (Stenmark, Catani, Neuner, Elbert, \& Holen, 2013).

\section{Conclusions}

- PTSD and associated psychosomatic symptoms are highly prevalent among the refugee population, especially among survivors of violence

- The policy context and policies around integration have an impact on sense of well-being and access to social services of refugees

- Social network interventions can be adapted and used among vulnerable groups like refugees and SGBV survivors

\section{Abbreviations}

FEDASIL Federal Agency for the Reception of Asylum seekers

PTSD Post-traumatic stress disorder

SGBV Sexual and gender based violence

\section{Declarations}

Ethics approval and consent to participate: Ethics approval was obtained from the Committee for Medical Ethics, Ghent University Teaching Hospital (EC/2016/1252). Consent for participation in the study was obtained from research participants using an informed consent form.

Consent for publication: Consent for publication was obtained from research participants using the informed consent form.

Availability of data and material: The datasets generated and/ analysed during the current study are not publicly available, as the data for this study are transcript interviews with pseudonymized information that might be re-identifiable. However they are available from the corresponding author on reasonable request.

Competing interests: The authors declare no competing interests

Funding: Funding for this project was obtained from Ghent University BOF Startkrediet (BOF.STA.2016.0031.01

Authors' contributions: Emilomo Ogbe designed the study, developed the analytical framework, conducted interviews, analysed the data and drafted the manuscript, Alaa Jbour conducted interviews, analysed the data and reviewed the manuscript, Ladan Rahbari and Maya Unnithan reviewed the data and provided 
technical inputs into the manuscript and analysis. Olivier Degomme supervised the development of the study, co-conceptualised the analytical framework, reviewed the paper and provided technical insight into the manuscript.

Acknowledgements: We would like to acknowledge Vincent Vannetelbosch, Ana Mauleon and Simon Schopohl for their input into the development of the theoretical model. Dr. Khalid Zurmati for his technical insights into the medical and psychosocial needs of refugees, Ines Keygnaert for providing technical information on recruitment strategies, Anne-Marie Hoogweys for technical insights into the research and for facilitating the fieldwork, Kris Vanduffel, Dr. Alexandra Moonaas and Servaas Congreacht for assisting with the coordination of fieldwork, Rukoundo Vincent and Gloria Imanishimwe for being excellent volunteers for my research.

\section{References}

Adam, I., \& Jacobs, D. (2014). Divided on immigration, two models for integration. The multilevel governance of immigration and integration in Belgium. In The Politics of Immigration in Multi-Level States (pp. 65-85): Springer.

Asgary, R., \& Segar, N. (2011). Barriers to health care access among refugee asylum seekers. Journal of Health Care for the Poor and Underserved, 22(2), 506-522.

Burnett, A., \& Peel, M. (2001). Asylum seekers and refugees in Britain: Health needs of asylum seekers and refugees. BMJ: British Medical Journal, 322(7285), 544.

Flury, M., \& Nyberg, E. (2010). Domestic violence against women: definitions, epidemiology, risk factors and consequences. Swiss medical weekly, 140(3536).

Goodman, L. A., \& Smyth, K. F. (2011). A call for a social network-oriented approach to services for survivors of intimate partner violence. Psychology of Violence, 1(2), 79.

Hogan, B. E., Linden, W., \& Najarian, B. J. C. p. r. (2002). Social support interventions: Do they work? , 22(3), 381-440.

Katerndahl, D., Burge, S., Ferrer, R., Becho, J., \& Wood, R. (2013). Differences in social network structure and support among women in violent relationships. Journal of interpersonal violence, 28(9), 1948-1964.

Kelly, J. A., St Lawrence, J. S., Diaz, Y. E., Stevenson, L. Y., Hauth, A. C., Brasfield, T. L., . . Andrew, M. E. (1991). HIV risk behavior reduction following intervention with key opinion leaders of population: an experimental analysis. American Journal of Public Health, 81(2), 168-171.

Laban, C. J., Gernaat, H. B., Komproe, I. H., Schreuders, B. A., \& De Jong, J. T. (2004). Impact of a long asylum procedure on the prevalence of psychiatric disorders in Iraqi asylum seekers in The Netherlands. The Journal of nervous and mental disease, 192(12), 843-851. 
Latkin, C. A., Sherman, S., \& Knowlton, A. (2003). HIV prevention among drug users: outcome of a network-oriented peer outreach intervention. Health psychology, 22(4), 332.

Levendosky, A. A., Bogat, G. A., Theran, S. A., Trotter, J. S., Eye, A. v., \& Davidson, W. S. (2004). The social networks of women experiencing domestic violence. American journal of community psychology, 34(1-2), 95-109.

Lloyd, A. (2014). Building information resilience: how do resettling refugees connect with health information in regional landscapes-implications for health literacy. Australian Academic \& Research Libraries, 45(1), 48-66.

McFarlane, J., \& Wiist, W. (1997). Preventing abuse to pregnant women: implementation of a'mentor mother'advocacy model. Journal of Community Health Nursing, 14(4), 237-249.

Pulinx, R., \& Van Avermaet, P. (2015). Integration in Flanders (Belgium)-Citizenship as achievement: How intertwined are 'citizenship'and 'integration'in Flemish language policies? Journal of Language Politics, 14(3), 335-358.

Pulvirenti, M., \& Mason, G. (2011). Resilience and survival: Refugee women and violence. Current Issues in Criminal Justice, 23(1), 37-52.

Rachel C. Shelton, Matthew Lee, Laura E. Brotzman, Danielle M. Crookes, Lina Jandorf, Deborah Erwin, \& Gage-Bouchard, E. A. (2019). Use of social network analysis in the development, dissemination, implementation, and sustainability of health behavior interventions for adults: A systematic review. Social Science \& Medicine, 220, 81-101. Retrieved from https://doi.org/10.1016/j.socscimed.2018.10.013.

Schwarzer, R., \& Leppin, A. (1991). Social support and health: A theoretical and empirical overview. Journal of social and personal relationships, 8(1), 99-127.

Smith, L. R. (2013). Female refugee networks: Rebuilding post-conflict identity. International Journal of Intercultural Relations, 37(1), 11-27.

Stenmark, H., Catani, C., Neuner, F., Elbert, T., \& Holen, A. (2013). Treating PTSD in refugees and asylum seekers within the general health care system. A randomized controlled multicenter study. Behaviour research and therapy, 51(10), 641-647.

Sullivan, C. M., \& Bybee, D. I. (1999). Reducing violence using community-based advocacy for women with abusive partners. Journal of consulting and clinical psychology, 67(1), 43.

Valente, T. W. (2012). Network interventions. Science, 337(6090), 49-53.

Vissenberg, C., Stronks, K., Nijpels, G., Uitewaal, P., Middelkoop, B., Kohinor, M., . . Nierkens, V. (2016). Impact of a social network-based intervention promoting diabetes self-management in 
socioeconomically deprived patients: a qualitative evaluation of the intervention strategies. BMJ open, 6(4), e010254.

Weine, S., Kulauzovic, Y., Klebic, A., Besic, S., Mujagic, A., Muzurovic, J., . . . therapy, f. (2008). Evaluating a multiple-family group access intervention for refugees with PTSD. 34(2), 149-164.

\section{Tables}

TABLE 1: Summary of information about centres and observation activities at study sites 


\begin{tabular}{|c|c|c|c|c|}
\hline $\begin{array}{l}\text { Name } \\
\text { of } \\
\text { centre }\end{array}$ & $\begin{array}{l}\text { Description of } \\
\text { centre }\end{array}$ & Type of centre & Activities done/observed & $\begin{array}{l}\text { Length of } \\
\text { observation }\end{array}$ \\
\hline $\begin{array}{l}\text { Centre } \\
1\end{array}$ & $\begin{array}{l}\text { Capacity of } 250 \\
\text { people. Mix of } \\
\text { families and } \\
\text { single men and } \\
\text { women. No } \\
\text { specific spaces } \\
\text { for males and } \\
\text { females }\end{array}$ & Open-access centre & $\begin{array}{l}\text { Consultations with the } \\
\text { doctors, nurses, social } \\
\text { workers and education } \\
\text { workers. Provided support } \\
\text { for clinic consultations and } \\
\text { spoke with and interviewed } \\
\text { refugees at the centre }\end{array}$ & $\begin{array}{l}6 \text { weeks: } \\
\text { November } \\
\text { to } \\
\text { December } \\
2016 \\
\text { (Centre } \\
\text { closed } \\
\text { February } \\
\text { 2017) }\end{array}$ \\
\hline $\begin{array}{l}\text { Centre } \\
2\end{array}$ & $\begin{array}{l}\text { Capacity of } 85 \\
\text { Majority of the } \\
\text { population, } \\
\text { unaccompanied } \\
\text { minors Mostly } \\
\text { single males, no } \\
\text { family present } \\
\text { during the } \\
\text { duration of } \\
\text { observation }\end{array}$ & Open-access centre & $\begin{array}{l}\text { Consultations with social } \\
\text { workers and education } \\
\text { workers, engaged in social } \\
\text { activities with the refugees, } \\
\text { cooking and outdoor } \\
\text { activities, organized a sexual } \\
\text { health workshop/ focus group } \\
\text { discussion at the centre }\end{array}$ & $\begin{array}{l}9 \text { months: } \\
\text { May } 2017 \\
\text { to March } \\
2018,5-8 \\
\text { hours per } \\
\text { week }\end{array}$ \\
\hline $\begin{array}{l}\text { Centre } \\
3\end{array}$ & $\begin{array}{l}\text { Capacity of } 850 \\
\text { people, mixed } \\
\text { population of } \\
\text { families and } \\
\text { single persons }\end{array}$ & $\begin{array}{l}\text { The centre has gates and a badge } \\
\text { is used to enter and leave the } \\
\text { centre, refugees had to take } \\
\text { permission to leave the centre and } \\
\text { were allowed to stay outside the } \\
\text { centre for only a certain amount of } \\
\text { days. In many ways felt like a } \\
\text { closed gated camp }\end{array}$ & $\begin{array}{l}\text { Consultations with health } \\
\text { care providers, multi- } \\
\text { disciplinary team meetings. } \\
\text { Informal discussions with } \\
\text { refugees at the waiting room } \\
\text { and the courtyard }\end{array}$ & $\begin{array}{l}1 \text { year: May } \\
2017 \text { to } \\
\text { May 2018: } \\
\text { 6-10 hours/ } \\
\text { week }\end{array}$ \\
\hline
\end{tabular}


Table 2: Key characteristics of the centre 


\begin{tabular}{|c|c|c|c|c|c|}
\hline $\begin{array}{l}\text { Type } \\
\text { of } \\
\text { centre }\end{array}$ & $\begin{array}{l}\text { Service } \\
\text { providers } \\
\text { available } \\
\text { 'in } \\
\text { house' }\end{array}$ & $\begin{array}{l}\text { Availability } \\
\text { of protocol } \\
\text { to address } \\
\text { violence }\end{array}$ & $\begin{array}{l}\text { GBV / Torture } \\
\text { referral pathway }\end{array}$ & $\begin{array}{l}\text { Commonly used } \\
\text { GBV / Torture } \\
\text { interventions }\end{array}$ & Key challenges \\
\hline $\begin{array}{l}\text { Centre } \\
1\end{array}$ & Yes & No & $\begin{array}{l}\text { Reports to } \\
\text { doctor/ Social } \\
\text { assistant, } \\
\text { reviewed and } \\
\text { then referred to } \\
\text { psychologist }\end{array}$ & $\begin{array}{l}\text { Referral to } \\
\text { psychologist, } \\
\text { transfer to } \\
\text { another centre, } \\
\text { to separate the } \\
\text { perpetrator } \\
\text { from the } \\
\text { survivor in } \\
\text { cases of } \\
\text { domestic } \\
\text { violence/ } \\
\text { interpersonal } \\
\text { violence }\end{array}$ & $\begin{array}{l}\text { No defined protocol for addressing } \\
\text { gender-based violence or torture. } \\
\text { Clear pathways and action plans not } \\
\text { defined. Made harmonization of } \\
\text { practices and responses difficult } \\
\text { across different service providers }\end{array}$ \\
\hline $\begin{array}{l}\text { Centre } \\
2\end{array}$ & No & No & $\begin{array}{l}\text { Discuss with the } \\
\text { social assistant } \\
\text { and then refer to } \\
\text { a psychologist if } \\
\text { needed/requested }\end{array}$ & $\begin{array}{l}\text { Referral to } \\
\text { specialists, } \\
\text { transfer } \\
\text { survivor to a } \\
\text { quieter centre, } \\
\text { if survivor has } \\
\text { symptoms of } \\
\text { PTSD or other } \\
\text { mental health } \\
\text { problems }\end{array}$ & $\begin{array}{l}\text { Disclosure was difficult and rare, } \\
\text { especially as this centre had mostly } \\
\text { males, stigma around gender-based } \\
\text { violence and PTSD in males, made } \\
\text { help seeking behaviour rare. No } \\
\text { defined protocol and pathway of } \\
\text { care was available }\end{array}$ \\
\hline $\begin{array}{l}\text { Centre } \\
3\end{array}$ & Yes & Yes & $\begin{array}{l}\text { Refer to the } \\
\text { doctor for }\end{array}$ & $\begin{array}{l}\text { Refer to } \\
\text { psychologist, }\end{array}$ & $\begin{array}{l}\text { Rates of disclosure was very low. } \\
\text { Language translations served as a }\end{array}$ \\
\hline
\end{tabular}




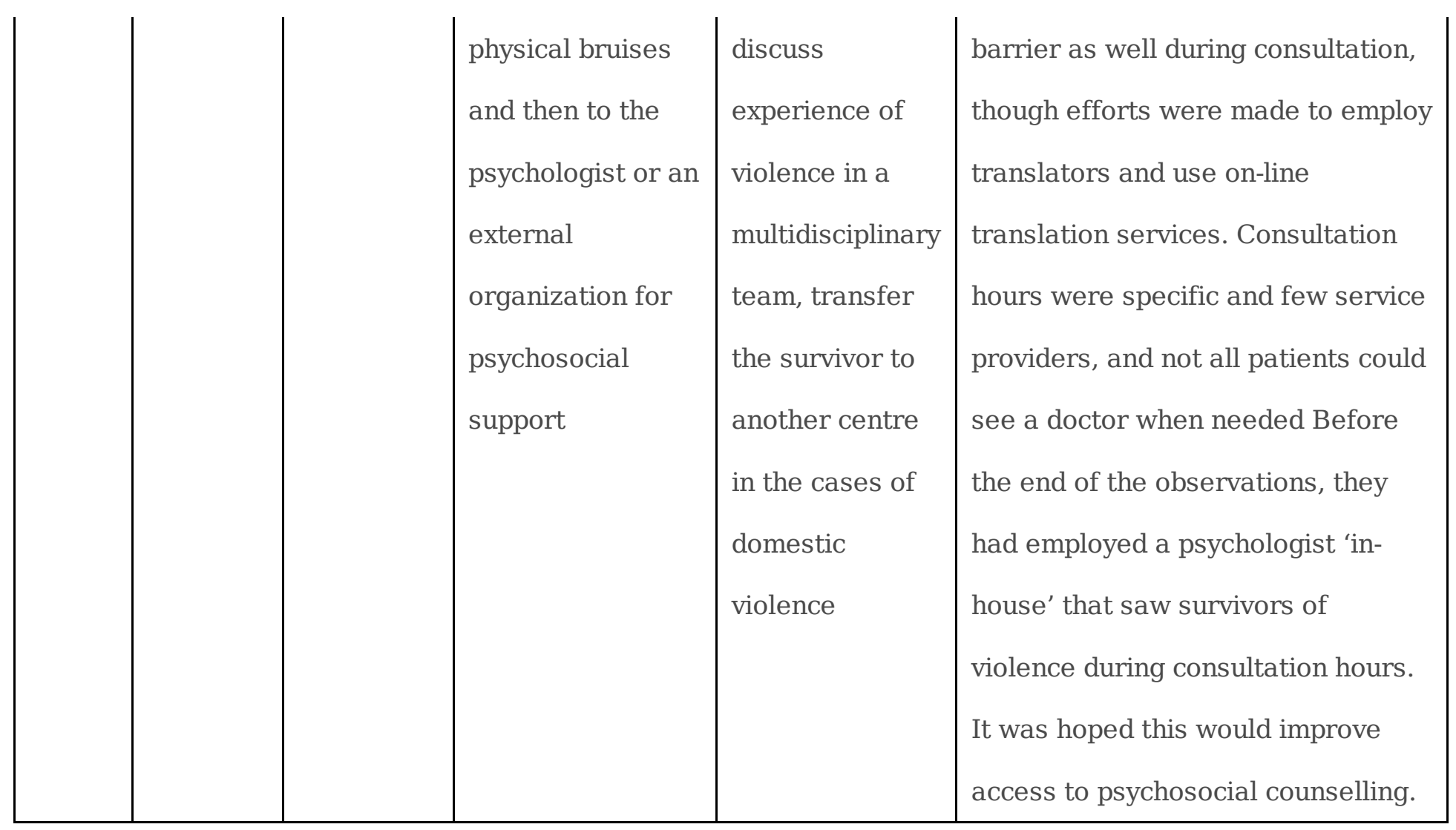

Table 3: Information about research participants

\begin{tabular}{|l|l|}
\hline Type of respondent & Number \\
\hline Social worker & 4 \\
\hline Medical doctors and psychologist (1) & 5 \\
\hline Nurses & 3 \\
\hline Refugees & 13 \\
\hline Medical directors & 2 \\
\hline Total & 27 \\
\hline
\end{tabular}

\section{Figures}




\section{Network effects on decision making of SGBV survivors (E.Ogbe et al 2018)}

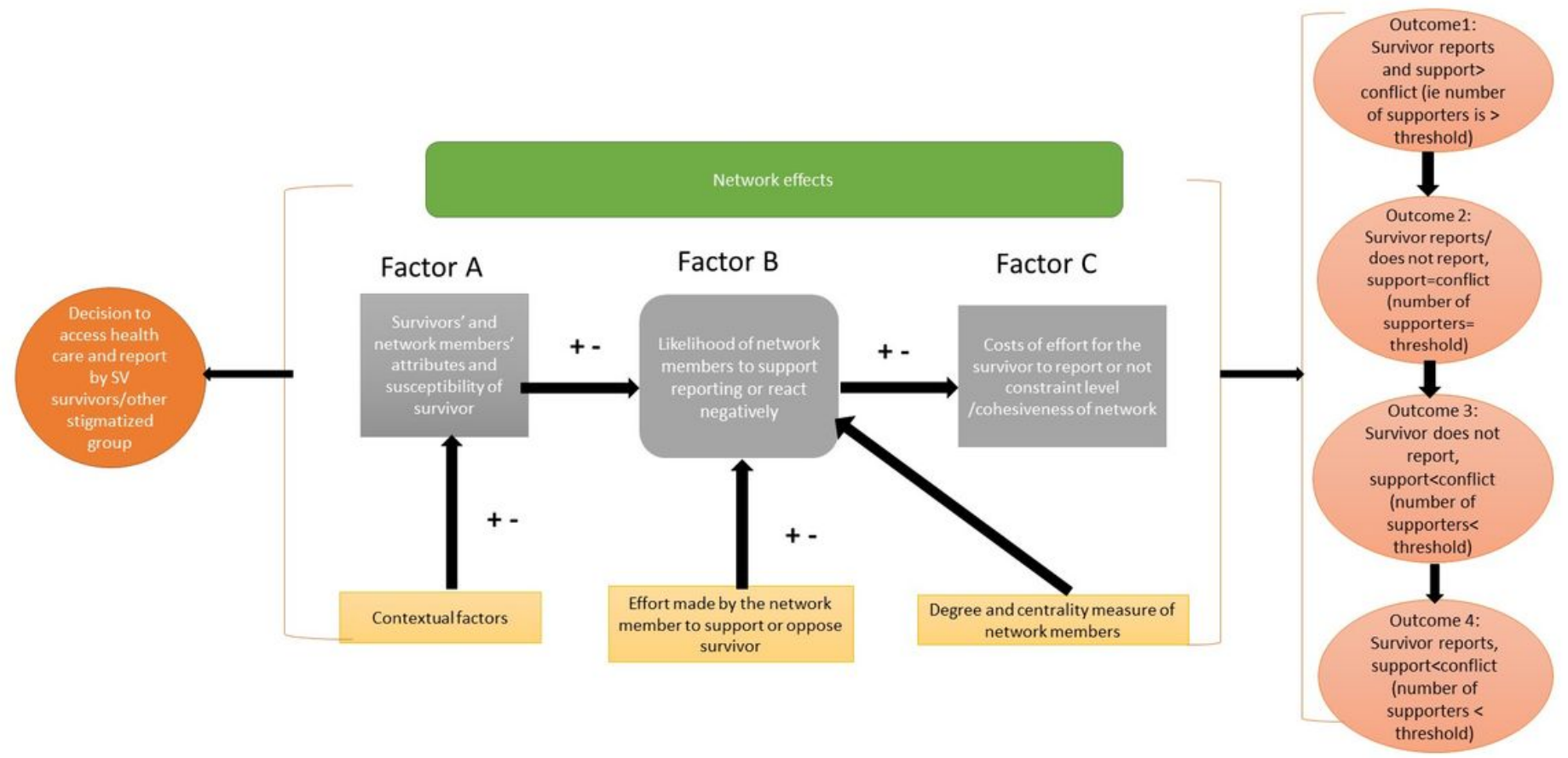

\section{Figure 1}

Model explaining network effects on reporting behaviour of sexual violence survivors (Ogbe et al 2018) 